\title{
Chronic diarrhea: the tip of the Iceberg
}

\begin{abstract}
Chronic diarrhea (CD) is a very common gastroenterological manifestation. However, the multiplicity of etiologies and the lack of standard approach strategies in these patients pose major diagnostic challenges. We present the clinical case of a 76-year-old woman with CD with 2years of evolution. Stool examination and colonoscopy had no abnormalities. The upper digestive endoscopy and duodenal biopsies revealed giardiasis and lymphoid hyperplasia. Anti-neutrophil cytoplasmic antibodies (ANCA), Anti-Saccharomyces cerevisiae antibodies (ASCA), anti-endomysium and viral serologies were negative. Analytically we found hypoproteinemia, hypogammaglobulinemia (A G and M), and lack of tetanus toxoid immunity and low memory B cells on peripheral blood phenotyping. Lymphoproliferative disease was excluded after further study. The final diagnosis was of Variable Common Immunodeficiency. The patient started immune globulins replacement with resolution of the diarrhea.
\end{abstract}

The purposes of this case are to demonstrate the general approach in a patient with CD and to alert to a rare cause with a late onset.

Keywords: diarrhea, common variable immunodeficiency, lymphoid hyperplasia, giardiasis
Volume 12 Issue I - 202I

\author{
Sara Joana Faria, Ana Sofia Costa, Teresa \\ Alfaiate, Isabel Bessa, Amélia Pereira \\ Department of Internal Medicine, Figueira da Foz District \\ Hospital, Portugal
}

\begin{abstract}
Correspondence: Sara Joana Faria, Internal Medicine's Department of Figueira da Foz District Hospital, Rot. do hospital, 3094-00I, São Pedro, Figueira da Foz, Coimbra, Portugal,Tel 23340200,Email sarajoanafaria@gmail.com

Ana Sofia Costa, Department of Figueira da Foz District Hospital, Rot. do hospital, 3094-00 I, São Pedro, Figueira da Foz, Coimbra, Portugal, Tel +351915186182,

Email asf.costa@hotmail.com
\end{abstract}

Received: January 18, 2021 | Published: Febrauary 03, 2021
Abbreviations: CD, chronic diarrhea; ANCA, antineutrophil cytoplasmic antibodies; ASCA, anti-saccharomyces cerevisiae antibodies; CRP, C-reactive protein; EBV, epstein barr; CVID, common variable immunodeficiency; IVIG, intravenous immunoglobulins; NLH, nodular lymphoid hyperplasia

\section{Introduction}

Chronic diarrhea (CD) is common and the form of presentation of a wide spectrum of pathologies. It is defined by persistent change in the consistency of stools or an increase in the frequency of daily stools ( $\geq 3$ ), lasting for more than 4 weeks. ${ }^{1-3}$ There are few epidemiological studies on the prevalence of CD over 65years of age (estimated values between 9.6 and 14.2\%). ${ }^{3}$ In developed countries, the causes are rarely infectious in immunocompetent adults and the main causes differ between young people and the elderly. ${ }^{2,3}$ The physician should initially consider the most common hypotheses in the elderly such as malignancy, iatrogenic diarrhea and fecal incontinence, and then look for less frequent causes. ${ }^{1-3}$

The objective of this clinical case is to demonstrate the diagnostic approach of $\mathrm{CD}$ in the elderly, which starts with the most frequent to the rarest causes, with a final diagnosis in this clinical case a little bit out of the box.

\section{Material and methods}

A 76-year-old woman was referred for CD (liquid dejections, more than 2 per day, without mucus or blood) and abdominal pain of 2 years of evolution, with worsening in the last 3 months. She had marked weight loss ( $10 \%$ of usual weight) but denied fever, night sweats, rash or other constitutional symptoms. From the past history she reported colic diverticulosis, hemorrhoidal disease and cholecystectomy. She was medicated with amitriptyline, mebeverine and loperamide. No consumption of tobacco, alcohol or herbal products was found and there was no history of recent trips.

Prior to the consultation, the previous assistant physician ordered stool examinations (bacteriological, mycological and parasitological) as well as viral serologies (hepatitis $\mathrm{B} / \mathrm{C}$ and human immunodeficiency virus [HIV]) that were negative. The patient also brought a normal colonoscopy and a computed tomography-guided enterography which revealed diverticulosis and adenomegaly at the root of the mesentery.

On physical examination, the patient was hemodynamically stable, with a body mass index (BMI) of $18 \mathrm{~kg} / \mathrm{m}^{2}$. The thyroid was not palpable and there were also no palpable peripheral adenopathies. Cardiopulmonary auscultation was normal and the abdomen had no tender points on palpation, organomegaly or masses. Rectal examination revealed only the presence of external hemorrhoids. No complaints of pruritus, bleeding or visible thrombosis were found.

\section{Results}

We carried out a complete analytical study with complete blood count, leukogram and biochemistry, that demonstrated normochromic normocytic anemia (hemoglobin: $12 \mathrm{~g} / \mathrm{dL}$ ), a slight increase in C-reactive protein (CRP) $(9.5 \mathrm{mg} / \mathrm{L})$, a decrease in total proteins $(6.1 \mathrm{~g} / \mathrm{L})$ and normal albumin $(4.4 / \mathrm{dL})$ (Table 1$)$.

Table I Analytical values in the first evaluation of the patient

\begin{tabular}{lll}
\hline Parameters & Value & Reference values \\
\hline Leukocytes & $8 \times 10^{3} / \mu \mathrm{L}$ & $4-10.5 \times 10^{3} / \mu \mathrm{L}$ \\
Hemoglobin & $12 \mathrm{~g} / \mathrm{dL}$ & $12.5-16 \mathrm{~g} / \mathrm{dL}$ \\
MCV & $80 \mathrm{fL}$ & $78-100 \mathrm{fL}$ \\
MCHC & $33.8 \mathrm{~g} / \mathrm{dL}$ & $32-36 \mathrm{~g} / \mathrm{dL}$ \\
Platelets & $338 \times 10^{3} / \mu \mathrm{L}$ & $150-450 \times 10^{3} / \mu \mathrm{L}$ \\
OGT & $18 \mathrm{U} / \mathrm{L}$ & $0-32 \mathrm{U} / \mathrm{L}$ \\
GPT & $15 \mathrm{U} / \mathrm{L}$ & $0-31 \mathrm{U} / \mathrm{L}$ \\
DHL & $379 \mathrm{U} / \mathrm{L}$ & $240-480 \mathrm{U} / \mathrm{L}$ \\
Alkaline Phosphatase & $98 \mathrm{U} / \mathrm{L}$ & $35-104 \mathrm{U} / \mathrm{L}$ \\
\hline
\end{tabular}


Table Continues...

\begin{tabular}{lll}
\hline Parameters & Value & Reference values \\
\hline Total bilirubin & $0.28 \mathrm{mg} / \mathrm{dL}$ & $<1 \mathrm{mg} / \mathrm{dL}$ \\
Direct bilirubin & $0.12 \mathrm{mg} / \mathrm{dL}$ & $0-0.3 \mathrm{mg} / \mathrm{dL}$ \\
GGT & $13 \mathrm{U} / \mathrm{L}$ & $5-36 \mathrm{U} / \mathrm{L}$ \\
Serum glucose & $99 \mathrm{mg} / \mathrm{dL}$ & $74-106 \mathrm{mg} / \mathrm{dL}$ \\
Urea nitrogen & $15.2 \mathrm{mg} / \mathrm{dL}$ & $8-23 \mathrm{mg} / \mathrm{dL}$ \\
Serum creatinine & $0.4 \mathrm{mg} / \mathrm{dL}$ & $0.5-0.9 \mathrm{mg} / \mathrm{dL}$ \\
Sodium & $142 \mathrm{mEq} / \mathrm{L}$ & $136-145 \mathrm{mEq} / \mathrm{L}$ \\
Potassium & $4.2 \mathrm{mEq} / \mathrm{L}$ & $3.5-5.1 \mathrm{mEq} / \mathrm{L}$ \\
Chloride & $101 \mathrm{mEq} / \mathrm{L}$ & $96-107 \mathrm{mEq} / \mathrm{L}$ \\
CRP & $9.5 \mathrm{mg} / \mathrm{L}$ & $<5 \mathrm{mg} / \mathrm{L}$ \\
Sedimentation rate & $12 \mathrm{~mm} / \mathrm{h}$ & $<20 \mathrm{~mm} / \mathrm{h}$ \\
Total proteins & $6.1 \mathrm{~g} / \mathrm{dL}$ & $6.4-8.3 \mathrm{~g} / \mathrm{dL}$ \\
Albumin & $4.4 \mathrm{~g} / \mathrm{dL}$ & $3.4-4.8 \mathrm{~g} / \mathrm{dL}$ \\
TSH & $1.57 \mu \mathrm{Ul} / \mathrm{mL}$ & $0.27-4.2 \mu \mathrm{Ul} / \mathrm{mL}$ \\
Calcium & $9.7 \mathrm{mg} / \mathrm{dL}$ & $8.4-9.7 \mathrm{mg} / \mathrm{dL}$ \\
\hline & & 0
\end{tabular}

CRP, C-reactive protein; DHL, dehydrogenase lactate; GGT, gama glutamyl transferase; GPT, glutamic-pyruvic transaminase; $\mathrm{MCHC}$, mean corpuscular hemoglobin concentration; MCV,mean corpuscular volume; OG,oxalacetic glutamic transaminase; thyroid stimulating hormone

†Bold-Altered results in relation to the reference values.

We ordered esophagogastroduodenoscopy (EGD) which showed "stomach with mild erythema and blurring of the gastric folds; duodenum with diffusely papular mucosa" (Figure 1). The biopsies performed revealed duodenal giardiasis, with nodular lymphoid hyperplasia (NLH). The patient started metronidazole cycle with no improvement.

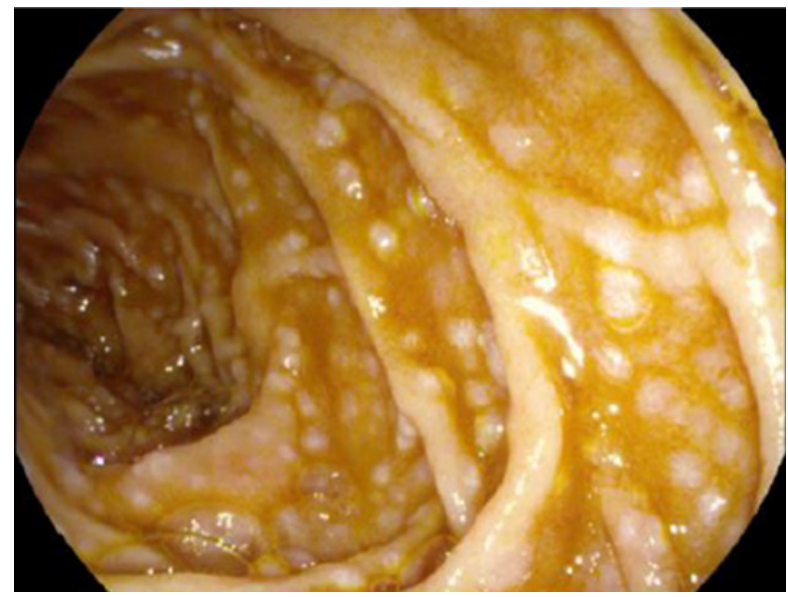

Figure I Upper Digestive Endoscopy showing duodenum with diffusely papular D2 mucosa.

After that, we extended the study and found negativity for ANCA, ASCA, antiendomysial antibodies and Epstein Barr (EBV) serologies, very low A, G and M immunoglobulins (Igs) (Table 2) and absence of immunity to tetanus toxoid. The phenotyping of peripheral blood showed $2 \%$ of memory $\mathrm{B}$ cells with $\operatorname{IgM}+/ \mathrm{IgD}+$ phenotype. We excised a lymph node from the mesocolon that histologically had nonspecific reactive characteristics. Bone biopsy and bone marrow phenotyping were unchanged.

Table 2 Immunoglobulin assay

\begin{tabular}{lll}
\hline Parameters & Value & Reference values \\
\hline IgA & $10 \mathrm{mg} / \mathrm{dL}$ & $70-400 \mathrm{mg} / \mathrm{dL}$ \\
IgG & $300 \mathrm{mg} / \mathrm{dL}$ & $700-1600 \mathrm{mg} / \mathrm{dL}$ \\
IgG subclasses & & \\
IgG I & $70 \mathrm{mg} / \mathrm{dL}$ & $405-1011 \mathrm{mg} / \mathrm{dL}$ \\
IgG2 & $56 \mathrm{mg} / \mathrm{dL}$ & $169-786 \mathrm{mg} / \mathrm{dL}$ \\
$\operatorname{IgG3}$ & $2 \mathrm{mg} / \mathrm{dL}$ & $11-85 \mathrm{mg} / \mathrm{dL}$ \\
$\operatorname{IgG} 4$ & $4.5 \mathrm{mg} / \mathrm{dL}$ & $3.9-86.4 \mathrm{mg} / \mathrm{dL}$ \\
IgM & $4 \mathrm{mg} / \mathrm{dL}$ & $40-230 \mathrm{mg} / \mathrm{dL}$ \\
$\operatorname{IgD}$ & $<1.3 \mathrm{mg} / \mathrm{dL}$ & $1.3-13.2 \mathrm{mg} / \mathrm{dL}$ \\
IgE & $<2 \mathrm{mg} / \mathrm{dL}$ & $<100 \mathrm{mg} / \mathrm{dL}$ \\
\hline
\end{tabular}

Ig-Immunoglobulin

† Bold-Altered results in relation to the reference values

After causes of secondary immunodeficiency have been excluded (including lymphoproliferative disease), we were finally able to make the diagnosis of Common Variable Immunodeficiency (CVID) and treat it appropriately. The patient started cycles of intravenous immunoglobulins (IVIG) and messalazine $3 \mathrm{~g}$ /day.

After 5 sessions of IVIG and with subsequent reconstitution of the immune system, the patient worsened with infectious diarrhea, this time with microbiological stools identification of Campylobacter jejuni (unmasked infection). After targeted therapy with azithromycin and metronidazole, the patient was discharged. She is currently doing cycles every 3 weeks of IVIG, with resolution of diarrhea, progressive recovery of appetite/weight and improvement of general condition.

\section{DISCUSSION}

The investigation of $\mathrm{CD}$ is a difficult process considering the multiplicity of etiologies. Therefore, a systematic approach with a good anamnesis, physical examination and a laboratory evaluation (complete blood count with leukogram, lipid profile, CRP, fecal calprotectin and microbiological study) is crucial ${ }^{1-3}$. Additional studies may be performed, such as tests for celiac disease, colonoscopy and EGD with biopsies, among others. ${ }^{2-4}$ In this clinical case, we move on to more specific studies because the patient already had complementary exams that were inconclusive.

EGD proved to be extremely important in this case by identifying giardiasis and NLH. Giardiasis, caused by a parasite (Giardia lamblia), is transmitted by drinking water contaminated with cysts. The diagnosis is made by microscopic observation of eggs, cysts or parasites in stools or by molecular detection techniques, in order to increase the sensitivity of the test. ${ }^{5}$ NLH is characterized by the presence of multiple nodules between 2 to $10 \mathrm{~mm}$ in diameter, and is associated with pathologies such as CVID, lymphomas, selective IgA deficiency, giardiasis, celiac disease, Helicobacter pylori infection and HIV. ${ }^{6}$ 
CVID is a primary immunodeficiency and is characterized by hypogammaglobulinemia. Clinical manifestations can occur at any age. However, most patients are diagnosed in childhood/young age because they have recurrent infections, including sinopulmonary infections. Some patients also have gastrointestinal disease, bacterial and parasitic infections such as giardiasis. ${ }^{7,8}$ The differential diagnosis is broad and includes malignancy (non-Hodgkin's lymphoma, chronic lymphocytic leukemia, multiple myeloma) congenital pathology and infectious pathology (HIV, EBV or cytomegalovirus). ${ }^{7}$

According to the criteria of Amerunga et al., ${ }^{9}$ the diagnosis is based on the existence of $\mathrm{G}$ hypogammaglobulinemia, exclusion of other causes of immune defect, age over 4years, absence or decreased memory B cells, absent or decreased response to vaccines, concomitant reduction in IgA and/or IgM and presence of histological markers suggestive of CVID (NLH of the intestine, granulomatous disease or diffuse interstitial pneumonitis). Treatment is based on the administration of IVIG. ${ }^{7,9}$

The combination of hypoproteinemia with duodenal giardiasis and NHL raised the suspicion of CVID. However, this diagnosis could only be sustained with the exclusion of more common pathologies such as lymphoma or celiac disease. For this reason, the patient underwent bone biopsy, bone marrow phenotyping, excision of a lymph node and autoimmunity study.

For the final diagnosis, and according to the criteria of Amerunga et al., ${ }^{9}$ we point out the following characteristics that justified the presence of CVID in this patient: presence of Giardia infection, duodenal NLH, hypogammaglobulinemia, lack of response to tetanus toxoid and low memory B cells. Thus, the diagnosis was made and the patient started first-line therapy with IVIG and messalazine with a good final outcome.

\section{Conclusions}

CVID is a primary immunodeficiency, with altered humoral immunity and characterized by hypogammaglobulinemia. It typically occurs at young ages with recurrent infections. Gastrointestinal manifestations are not the most frequent but also occur.

This case is interesting because it has a clinically evident manifestation of CVID in a very late age group. However, it is important to keep in mind that if the diagnostic investigation of CD is narrowing from the most frequent to the rarest causes, we always end up arriving at the diagnosis and the appropriate treatment.

\section{Acknowledgments}

None.

\section{Conflicts of interest}

The authors declare that there are no conflicts of interest.

\section{Funding}

None.

\section{References}

1. Schiller LR, Pardi DS, Sellin JH. Chronic Diarrhea: Diagnosis and Management. Clin Gastroenterol Hepatol. 2017;15(2):182-193.e3.

2. Arasaradnam RP, Brown S, Forbes A, et al. Guidelines for the investigation of chronic diarrhoea in adults: British Society of Gastroenterology, 3rd edition. Gut. 2018;67(8):1380-1399.

3. Schiller LR. Chronic Diarrhea Evaluation in the Elderly: IBS or Something Else? Curr Gastroenterol Rep. 2019;21(9):45.

4. Ludvigsson JF, Bai JC, Biagi F, et al. BSG Coeliac Disease Guidelines Development Group; British Society of Gastroenterology. Diagnosis and management of adult coeliac disease: guidelines from the British Society of Gastroenterology. Gut. 2014;63(8):1210-1228.

5. Minetti C, Chalmers RM, Beeching NJ, et al. Giardiasis. BMJ. 2016;355:i5369.

6. Albuquerque A. Nodular lymphoid hyperplasia in the gastrointestinal tract in adult patients: A review. World J Gastrointest Endosc. 2014;6(11):534540 .

7. Bonilla FA, Barlan I, Chapel H, et al. International Consensus Document (ICON): Common Variable Immunodeficiency Disorders. J Allergy Clin Immunol Pract. 2016;4(1):38-59.

8. Uzzan M, Ko HM, Mehandru S, et al. Gastrointestinal Disorders Associated with Common Variable Immune Deficiency (CVID) and Chronic Granulomatous Disease (CGD). Curr Gastroenterol Rep. 2016;18(4):17.

9. Ameratunga R, Woon ST, Gillis D, et al. New diagnostic criteria for CVID. Clin Exp Immunol. 2013;174(2):203-211. 